\title{
Determination of Lignin Modifying Enzymes from Pleurotus ostreatus and Lentinus squarrosulus
}

\author{
S. B. Chuku ${ }^{1 *}$, E. O. Nwachukwu ${ }^{1}$, I. O. Agbagwa ${ }^{1}$ and H. O. Stanley ${ }^{2}$ \\ ${ }^{1}$ Department of Plant Science and Biotechnology, University of Port Harcourt Rivers State, Nigeria. \\ ${ }^{2}$ Department of Microbiology, University of Port Harcourt Rivers State, Nigeria.
}

\begin{abstract}
Authors' contributions
This work was carried out in collaboration among all authors. Author SBC designed the study, performed the statistical analysis, wrote the protocol and wrote the first draft of the manuscript. Authors EON and IOA managed the analyses of the study. Author HOS managed the literature searches. All authors read and approved the final manuscript.

Article Information

DOI: 10.9734/ARRB/2021/v36i630388

Editor(s):

(1) Dr. Md. Torequl Islam, Federal University of Piaui, Brazil.

Reviewers:

(1) Ovat Innocent Ovat, Cross River University of Technology, Nigeria. (2) Bárbara Cristina Félix Nogueira, Universidade Federal de Viçosa, Brazil. Complete Peer review History: http://www.sdiarticle4.com/review-history/67853
\end{abstract}

Original Research Article

Received 01 March 2021

Accepted 04 May 2021

Published 23 June 2021

\begin{abstract}
Fungi play vital roles as decomposers. White rot fungi are an eco-physiological group that degrades wood by the secretion of specialized extracellular enzymes including lignin-modifying enzymes. There is growing interest in the use of extracellular enzymes for bioremediation. This study determined the Lignin Modifying Enzymes (LMEs) associated with two species of mushroom, Pleurotus ostreatus and Lentinus squarrosulus. The qualitative study was conducted using agar medium substituted with chromogenic substances to determine the production of LMEs by the species. The appearance of colour change and clearance due to reaction with chromogenic substrates were used to determine LMEs production by the fungi. The results showed that Pleurotus ostreatus and Lentinus squarrosulus tested positive by the appearance of light brown colouration, reddish-brown colouration and discolouration of media for overall polyphenol oxidase, Laccase and Peroxidase activity, respectively. The study showed that the species studied are candidates for large scale production of LMEs that can be utilized as an eco-friendly solution for bioremediation of contaminated sites.
\end{abstract}

Keywords: bioremediation; laccase; Lentinus squarrosulus; lignin modifying enzymes; Pleurotus ostreatus; peroxidase.

*Corresponding author: E-mail: sobomatechuku@gmail.com; 


\section{INTRODUCTION}

Fungi exhibit great diversity and play an important role in balancing ecosystems. They serve as both decomposers and recyclers, break down dead organic matters and release the nutrients back to the soil to enrich the soil for another fresh growth. This is made possible by exoenzymes released by the species [1]. Fungal enzymes are used in several industries like pharmaceutical, agricultural, food, paper, detergent, textile, waste treatment, and petroleum industries and more recently, bioremediation [2].

White rot fungi are a group of wood rotters that degrade lignin due to extracellular enzymes they release, which are mainly lignin peroxidase, manganese peroxidase and laccase [3]. They have the potential to be used as great biotechnological assets that can contribute to solving the problem of pollution. The enzymes have a broad substrate specificity hence their ability to mineralize a vast range of Persistent Organic Pollutants (POPs) such as industrial dyes, agrochemicals, polychlorinated biphenyl and Polycyclic Aromatic Hydrocarbons (PAHs) [4]. These enzymes have been reported to occur in different combinations in different white-rot fungi or even in the same fungus under different conditions $[5,6]$

Fungal treatment of wastes and pollutants is cheaper than the use of chemicals [7] and it is an environmentally friendly approach. Their enzymatic and absorption abilities make fungi a great tool for remediation. The mycelia carry out natural processes capable of environmental remediation. In addition to their ability to produce extracellular enzymes, fungi are known for their prolific growth, good biomass production, and extensive hyphae reach in the environment [8]. Fungal bioremediation is mainly carried out by white-rot fungi [9].

The study was conducted to determine the production of Lignin Modifying Enzymes by two species of mushrooms, Pleurotus ostreatus and Lentinus squarrosulus. The species used were screened for overall lignin modifying enzyme, laccase, and overall peroxidases.

\section{MATERIALS AND METHODS}

The fungi species (indigenous mushrooms) used for this work were obtained from Bio-resources Development Centre, Odi, Bayelsa State. The samples were labelled as samples 1 and 2 during collection. These were transported to the laboratory immediately in zip lock bags.

\subsection{Preparation of Culture Medium}

Potato Dextrose Agar (PDA) was used for tissue culture. This was prepared following the manufacturer's instruction using the PDA powder (Hi-Media). After autoclaving, the media was left to cool and Chloramphenicol $0.1 \%(\mathrm{w} / \mathrm{v})$ was added to prevent bacterial contamination. The solution was properly homogenized and poured into the Petri dishes aseptically and allowed to solidify.

\subsection{Tissue Culture}

The mushrooms were surface sterilized by wiping with $70 \%$ ethanol followed by sterile distilled water. Inner tissues of fresh mushrooms collected were excised in an already sterilized inoculation chamber with a naked flame. Tissue culture was achieved for each species following the method of Chuku et al. The plates were then incubated for 14 days in the dark at room temperature $27 \pm 2 \square$ C. Several subcultures to obtain a pure culture were done in each case.

\subsubsection{Overall screening for lignin modifying enzymes (Bavendamn's test)}

The culture medium used for this test was Lignin Basal Medium (LBM) as described by Pointing, 1999. The culturemedium was autoclaved at $121 \square \mathrm{C}$ for 15 minutes and supplemented with separately sterilized $20 \%$ (w/v) aqueous glucose solution and $1 \%(\mathrm{w} / \mathrm{v})$ aqueous tannic acid solution. $1 \mathrm{ml}$ of both were added to each $100 \mathrm{ml}$ of culture medium prepared. The mixture was properly homogenized, poured aseptically and allowed to solidify. The plates were inoculated at the centre with one test fungus each using a $7 \mathrm{~mm}$ diameter cork borer; an uninoculated plate with the culture medium served as a control in each case. The experiment was set up in triplicates for the mushroom species used. The set up was incubated at room temperature in darkness and examined daily for 10 days.

\subsection{Screening for Laccase by Plate Assay}

The culture medium used for the assay was PDA with the preparation as described above. In this case, during preparation, the medium was supplemented with $0.01 \%$ (v/v) guaiacol $[10,11]$. The Petri dishes were inoculated with one test fungus each using a $7 \mathrm{~mm}$ diameter cork borer at the centre and an uninoculated plate with the culture medium served as a control in each case. The experiment was set up in triplicates for the 
mushroom species used. The set up was incubated at room temperature in darkness and examined daily for 10 days.

\subsection{Screening for Total Peroxidase Activity by Plate Assay}

The screening for peroxidase activity was done using Malt Extract Agar (MEA) supplemented with $0.01 \%(\mathrm{w} / \mathrm{v})$ Azure B followed by $1 \mathrm{ml}$ of $20 \%$ $(\mathrm{w} / \mathrm{v})$ aqueous glucose solution per $100 \mathrm{ml}$ of medium prepared. The Petri dishes were inoculated with one test fungus each using a $7 \mathrm{~mm}$ diameter cork borer at the centre and an uninoculated Petri dishes with the culture medium served as a control in each case. The experiment was set up in triplicates for the mushroom species used. The set up was incubated at room temperature in darkness and examined daily for 10 days $[12,13]$.

\section{RESULTS AND DISCUSSION}

\subsection{Tissue Culture of Mushrooms}

The tissues started growing from the excised inner tissues of mushroom samples after 7 days of inoculation in sterile PDA. White mycelia of the samples were seen on the subculture plates from the third day of incubation; the plates became fully ramified by the $10 \pm 2$ days of incubation this is in line with the report of $[14,15]$. Mycelial growth of Pleurotus ostreatus and Lentinus squarrosulus is shown in Fig.1 ( $a$ and b). Sample 1 showed white mycelia made of a thick network of hyphae, giving it a velvety look. The mycelia grew radially radiating from the point of inoculation at the centre of the Petri dish (Fig. 1). Sample 2 had white mycelia that grew radially from the point of inoculation in steps until the Petri dishes were fully ramified (Plate 1). Similarly, Rawte and Diwan [16] and Kumla et al., [17] in their respective studies showed that PDA gave the best mycelial yield. Gregory et al., [18] recorded maximum biomass yield using PDA medium as substrate for tissue culture of Pleurotus spp. MEA was reported to supporting the best mycelial growth in Pleurotus species studied by Nasim et al., [19], Khandakar et al., [20] and Stanley and Nyenke, [21]. However, mycelial growth of fungus is highly dependent on the growth media and its composition [22].

\subsection{Overall Lignin Modifying Enzyme Activity}

From the set-up, the control showed a clear medium until the end of the incubation period of
10 days. The treatments with the different species showed a light brown colouration around the mycelial growth when viewed from the top and bottom of the Petri dishes. Pleurotus ostreatus showed a light brown colouration by the edge of the mycelial growth not extending so much (Plate $2 \mathrm{~b}$ and $\mathrm{c}$ ). Lentinus squarrusulus showed a light brown colouration that extended more than that of the other species (Plate $2 d$ and e). The light brown to pale yellow colouration indicated a positive reaction to overall lignin modifying enzyme activity. This is in line with the report of Pointing [23]. Similar studies carried out by Kameshwar and Qin [13] they stated that the appearance of the brown zone around the fungal colony represents the overall polyphenoloxidase activity. Similarly, Pandey et al.,[11] found a brown zone colour formation around the fungal colony in their screening of the overall lignin modifying enzyme activity. Fungal isolates produced dark yellow to brown colouration around fungal growth and was positive to tannic acid plate assay [24,25]. However, the production of brown colouration around the colony may be similar to many other fungal colourations [26]. Hence, the need for other plate assays alongside to determine specific lignin modifying enzymes. The results are shown in Plates 2 below.

\subsection{Screening for Laccase Enzyme on Agar Plate}

The colour change indicating the presence of laccase was observed by the third day of incubation and became wider and more intense by the day until the end of the incubation period when compared to the controls which gave a clear medium to the end of the experiment. Pleurotus ostreatus showed a thick reddishbrown colouration when viewed from the top of the Petri dish. When viewed from the bottom of the Petri dish, it showed a very dark red to black colouration in the middle, at the point of inoculation that got thinner towards the edges forming an orange coloured halo at the edge (Plate $3 b$ and $c$ ). The same pattern was also observed for Lentinus squarrusulus (Plate $3 \mathrm{~d}$ and e). All test fungi showed a positive indication of laccase production Viswanath et al., [27]. The colour change observed i.e orange halo, red to reddish-brown and black in the middle of the Petri dishes this is in line with the reports of Kiiskinen et al., [10]; Viswanath et al., [27]; Atalla et al., [28]; Sharma et al., [25]; Thiribhuvanamala et al., (2017). The colour change orange, red to reddish- brown and black in the middle is usually 
as a result of the oxidation of guaiacol by the laccase enzyme $[29,30,26]$. Kiiskinen et al., [10] in their investigation using different media types found MEA to be an excellent media for isolating laccase producing fungi also reported an excellent correlation of the presence of laccase activity with guaiacol and polymeric dyes (RBBR and Poly R-478), unlike Tannic acid which showed low specificity.

\subsection{Screening for Total Peroxidase Activity on Agar Plate}

The clearance zone was first observed about the seventh day of incubation and was more visible by the tenth day. The control gave a dark blue colouration till the end of the incubation period and gave a basis to compare. Pleurotus ostreatus showed a vigorous growth on the growth medium and as the day progressed from the seventh to tenth day, the growth medium became decolourized away from the point of inoculation (Plate $4 \mathrm{~b}$ and c). Lentinus squarrusulus showed a considerable good growth on the culture medium used with subsequent decolourization of the medium on the seventh day which became more visible by the tenth day (Plate $4 d$ and e). This reported decolourization or clearance indicates a positive reaction to total peroxidase production without the addition of hydrogen peroxide. The fungi cultures used decolourized the culture medium giving a positive result for peroxidase production. This is similar to results obtained by Reanprayoon and Pathyomsiriwong [31], Chaudhary et al. (2015), Kameshwar and Qin [13], and Sharma et al., [25]. The use of Azure B for peroxidase screening has an advantage over the use of other chromogenic substance (like guaiacol) as it does not require the addition of Hydrogen peroxide to the culture medium used for the assay [23] (Nayanashree and Thippeswamy, 2015). The medium used, MEA supplemented with Azure B supported the growth of mycelia of the species tested. The indication of peroxidase production which could be lignin peroxidase, manganese peroxidase, or both was determined by the appearance of a clearance zone in the test medium.

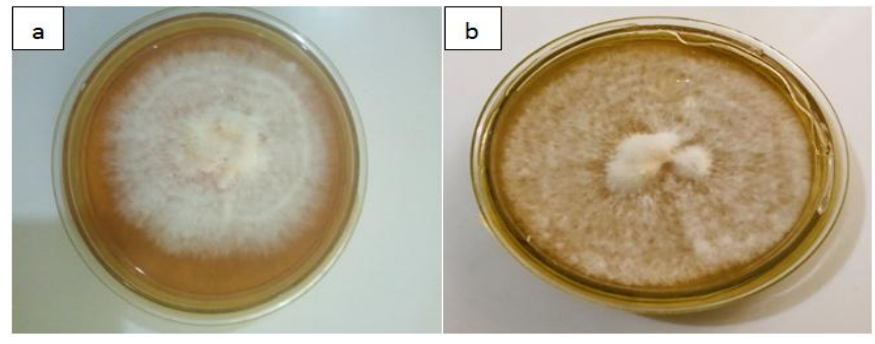

Fig. 1. Pure cultures of Pleurotus ostreatus (a)and Lentinus squarrosulus (b).

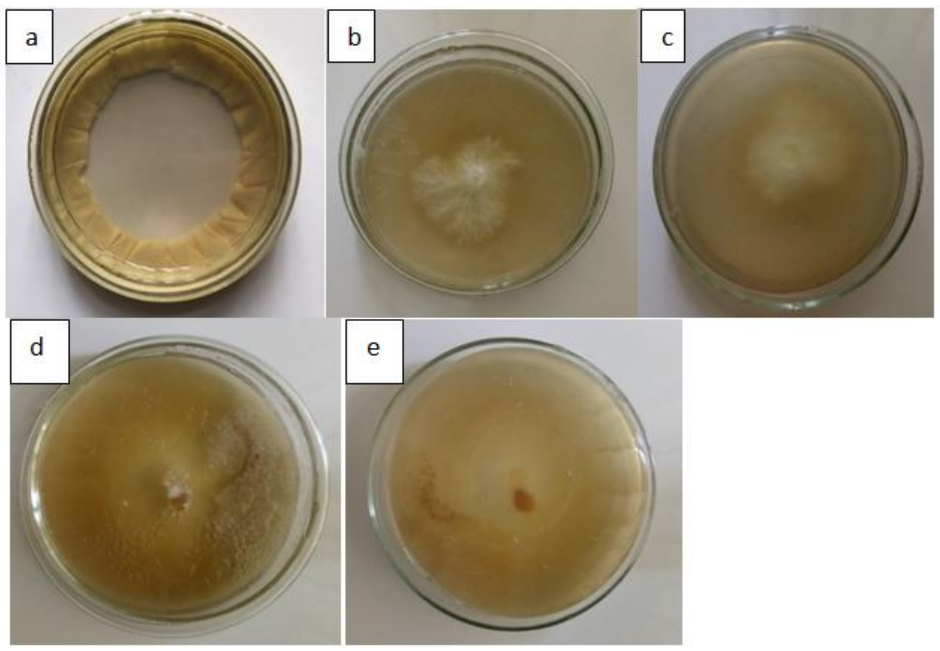

Fig. 2. Overall lignin modifying enzyme test: Control; (a) $P$. ostreatus front view; (b) $P$. ostreatus back view; (c) L. squarrosullus (front view); (d) L. squarrosullus (back view)(e) 


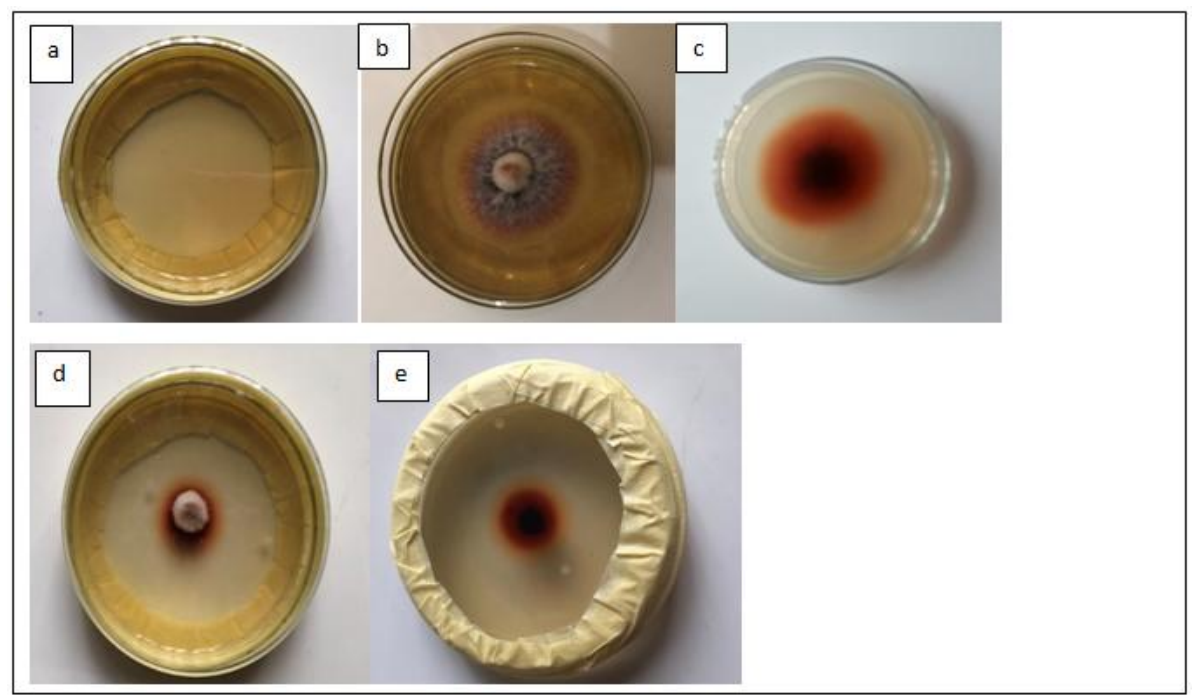

Fig. 3. Laccase test: Control (a), P. ostreatus (front view) (b), P. ostreatus (back view); (c), L. squarrosullus(front view) (d), L. squarrosullus (back view) (e)
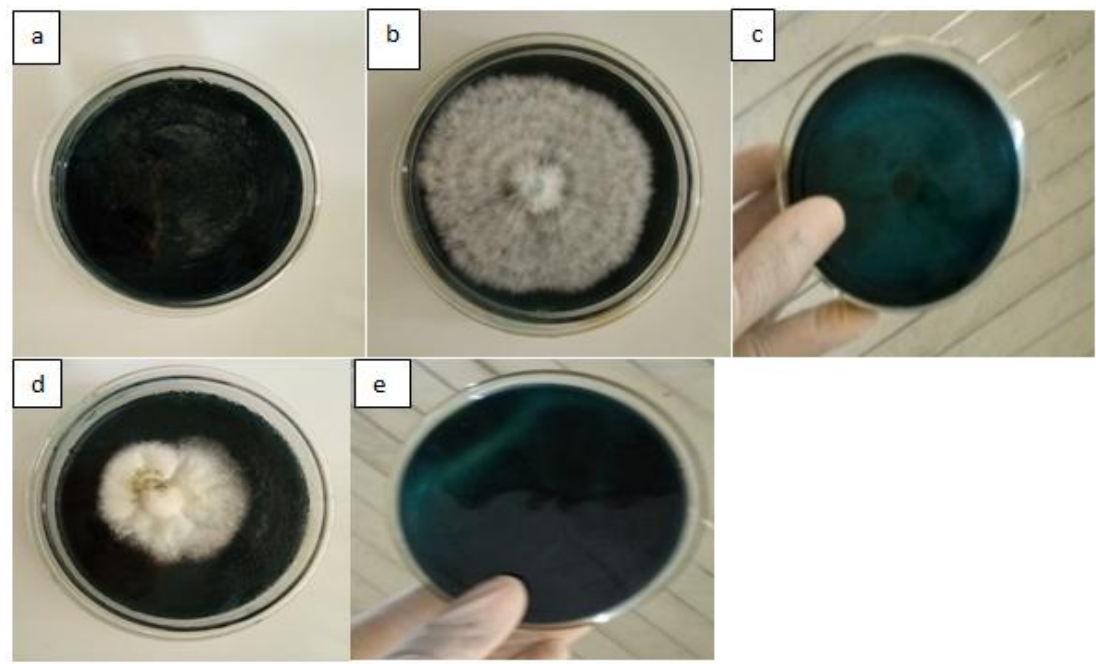

Fig. 4. Total Peroxidase Activity test: Control (a), P. ostreatus(front view) (b), $P$. ostreatus(back view) (c), L. squarrosullus(front view) (d), L. squarrosullus(back view) (e)

\section{CONCLUSION}

The test mushrooms gave positive results for all enzymes tested. The study showed that the species are candidates for large scale production of LMEs that can be utilized as an eco-friendly alternative for cleanup of polluted sites.

\section{COMPETING INTERESTS}

Authors have declared that no competing interests exist.

\section{REFERENCES}

1. Kakdek UB, Jamdhade VM. Studies on Fungi responsible for biodegradation and Humification of organic matter. Bionano Frontier. 2009;2(12):77-81.

2. Singh R, Kumar M, Mittal A, Mehta PK. Microbial enzymes: industrial progress in 21st century. 3 Biotech. 2016;6(2):174.

3. Kantharaj P, Boobalan B, Sooriamuthu S, Mani R. Lignocellulose Degrading Enzymes from Fungi and Their Industrial Applications. International Journal of 
Current Research and Review. 2017;9(21):1- 12.

4. Mansur M, Arias ME, Copa-Patiño JL, Flärdh M, González AE. The white-rot fungus Pleurotus ostreatus secretes laccase isozymes with different substrate specificities. Mycologia. 2003;95:10131020.

5. Krause DO, Denman SE, Mackie RI, Morrison M, Rae AL, Attwood GT, McSweeney CS. Opportunities to improve fibre degradation in the rumen: microbiology, ecology, and genomics. FEMS Microbiology Reviews. 2003;27:663-693.

6. Hammel K, Cullen D. Role of fungal peroxidases in biological ligninolysis. Current Opinion in Plant Biology. 2008;11, 349-55.

7. Jalc D. Straw Enrichment for Fodder Production by Fungi. Agricultural Applications. 2002;10:19-38.

8. Ashoka G, Geetha MS, Sullia SB. Bioleaching of composite textile dye effluent using bacterial consortia. Asian Journal Microbiology Biotechnology Environmental Science. 2002;4:65-68.

9. Singh $\mathrm{H}$. Mycoremediation: Fungal Bioremediation. Wiley, Hoboken; 2006.

10. Kiiskinen LL, Ratto M, Kruus K. Screening of Novel Laccase- Producing Microbes. Journal of Applied Microbiology. 2004;97:640-646.

11. Pandey RK, Rana B, Tewari S, Sarkar A, Dubey A, Chandra D, Tewari L. Exploration of plants- biomass-degrading fungi for in vitro mycoremediation of toxic synthetic dyes. International Journal of Current Microbiology and Applied Sciences. 2016;5(5): 581-592.

12. Archibald FS. A new assay for lignin-type peroxidases employing the dye Azure B. Applied and Environmental Microbiology. 1992;58:3110-3116.

13. Kameshwar AKS, Qin W. Qualitative and quantitative methods for isolation and characterization of lignin-modifying enzymes secreted by microorganisms. Bioenergy Research. 2016;10 (1):248-266.

14. Chuku SB, Nwachukwu EO, Stanley HO. Effects of selected culture media on mycelial growth of oyster mushroom (Pleurotus ostreatus). African Journal of Biotechnology. 2015;14(17):1471-1474.

15. Ishaq M, Fiaz M, Saifullah Ullah S, Khan BM. Evaluation of mycelial growth of oyster mushroom (Pleurotus floridanus Singer) on different media and cereal grains. Journal of Biodiversity and Environmental Sciences. 2017;11(3): 67-72.

16. Rawte H, Diwan R. Growth response of Pleurotus spp. on different basal media and different $\mathrm{pH}$ levels. Journal of Ecobiotechnology. 2011;3:10-12.

17. Kumla J, Suwannarac $N$, Jaiyase $A$, Bussaban B, Lumyong S. Development of an edible wild strain of Thai oyster mushroom for economic mushroom production. Chiang Mai Journal of Science. 2013;40:161-172.

18. Gregori A, Vagelj M, Pohleven J. Cultivation techniques and medicinal properties of Pleurotus spp. Food Technology and Biotechnology. 2007;45:238-249.

19. Nasim G, Malik SH, Bajwa R, Afzal M, Mian CG. Effect of three different culture media on mycelia growth of oyster Chinese mushroom. Journal of Biological Science. 2001;1:1130-1133.

20. Khandakar J, Yesmin S, Moonmoom M. Mycelial growth of Pleurotus citrinopileatus on different environmental condition. Bangladesh Journal of Mushroom. 2008;2:55-62.

21. Stanley $\mathrm{HO}$, Nyenke CU. Cultural studies on mycelia of Pleurotus plumonarius (oyster mushroom) in selected culture media. International Journal of Science and Nature. 2011;2:183-185.

22. Chang ST, Miles PG. Mushrooms: cultivation, nutritional value, medicinal effect, and environmental impact. 2nd ed., CRC Press. Boca Raton. 2004;24-451.

23. Pointing SB. Qualitative methods for the determination of lignocellulolytic enzyme production by tropical fungi. Fungal Diversity. 1999;2:17-33.

24. Gao H, Wang Y, Zhang W, Wang W, Mu Z. Isolation, identification and application in lignin degradation of an ascomycetes $\mathrm{GHJ}$ 4. African Journal of Biotechnology. 2011;10(20):4166- 4174.

25. Sharma A, Aggrawal NK, Yadav A. Isolation and screening of ligninolytic fungi from various ecological niches. Universal Journal of Microbiology Research. 2017;5:225-34.

26. Alfarra HY, Hasali NH, Omar MN. A Lignolytic fungi with laccase activity isolated from Malaysian Local environment for phyto-chemical transformation purposes. International Research Journal of Biological Sciences. 2013;(2): 1-6. 
27. Viswanath $B$, Chandra MS, Pallavi $H$, Reddy BR. Screening and assessment of laccase Producing fungi isolated from different environmental samples. African Journal of Biotechnology. 2008;7(8):11291133.

28. Atalla S, Kheiralla Z, Hamed E, Amani A, Abd El Aty A. Screening of some marinederived fungal isolates for lignin degrading enzymes (LDEs) production. Agriculture and Biology Journal of North America. 2010;1:591-599.

29. Agrawal N, Verma P, Singh RS, Shahi SK. Ligninolytic enzyme production by white rot fungi Poddoscyhpa elegans strain FTG4. International Journal of Current Microbiology and Applied Sciences. 2017a;6(5):2757-2754.

30. Agrawal N, Verma P, Singh RS, Shahi SK. Ganoderm lucidium: A potent source of ligninolytic enzyme production. International Journal of Advanced Research. 2017b;5(5):1977-1981.

31. Reanprayoon $P$, Pathomsiriwong W. Tropical soil fungi producing cellulase and related enzymes in biodegradation. Journal of Applied Sciences. 2012;12(8):19091916.

(C) 2021 Chuku et al.; This is an Open Access article distributed under the terms of the Creative Commons Attribution License (http://creativecommons.org/licenses/by/4.0), which permits unrestricted use, distribution, and reproduction in any medium, provided the original work is properly cited.

Peer-review history:

The peer review history for this paper can be accessed here: http://www.sdiarticle4.com/review-history/67853 